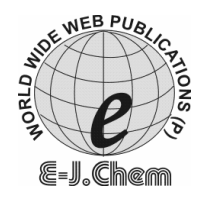

\title{
Development and Characterization of Novel Interpenetrating Network (IPN) Foams from Epoxy Ester and Aliphatic Epoxy Resin
}

\author{
KANUPRASAD PATEL ${ }^{*}$, DHIRUBHAI DESAI and SANTOSH BHUVA \\ Chemistry Department, \\ V. P. \& R. P. T. P. Science College, \\ Vallabh Vidyanagar - 388 120, Gujarat, India. \\ drkdpatel64@yahoo.co.in
}

Received 14 June 2008; Accepted 10 August 2008

\begin{abstract}
Diglycidyl ether of bisphenol-A (DGEBA) was reacted with acrylate monomer at variable molar ratios. The reaction between glycerine and epichlorohydrine form glycidyl ether of polyol aliphatic epoxy resin. The resultant resins were characterized duly. Both the resins were mixed at different ratios with constant high shear stirring. The obtained mixture and suitable additives were heated at $150{ }^{\circ} \mathrm{C}$ for one and half hour. The so called Interpenetrating Network (IPN) transformed into foams. The performance of foams was evaluated by testing for compression in both parallel and perpendicular to rise direction. The tests were carried out at room temperature and at the elevated temperature. The compression properties showed a decreasing trend for increasing amounts of glycerine resin. The density and thermal properties of epoxy foams were also evaluated. The relation between the composition, density and properties of the foam was analyzed.
\end{abstract}

Keywords: Epoxy ester, Interpenetrating network (IPN) foam, and Aliphatic epoxy resin.

\section{Introduction}

In the last 20-25 years, foam has been widely used where regular plastics cannot give satisfactory results. Polyurethane (PU) foam has many applications as a light weight structural material, but unfortunately there are most dangerous isocyanates materials have been used to manufacture the PU foams. It create serious health hazard even if exposure to very low concentration of these materials ${ }^{1-3}$. Epoxy foams are used in the production of surfboards, automobiles and railways carriages ${ }^{4}$. 
The interpenetrating polymer networks (IPNs) are novel type of polyblends consisting of two or more intertwined polymer chains in network form ${ }^{5}$. The IPNs are formed simultaneously or sequentially by independent reactions. Proper combination and interpenetration of polymer networks will enable to enhance certain properties which are otherwise difficult to achieve by chemical variations in the polymer chain. The IPNs synthesized by the combination of various chemical types of polymer network exhibit varying degrees of phase separation depending on the compatibility of component polymers ${ }^{6-8}$. Mechanical properties of the polymer blends with interpenetrating network structures are much higher than that of constituent polymers ${ }^{9,10}$. The processing and final physical properties of combinations of epoxy and curing agents depend primarily on their chemical composition and degree of cure. Gas blown foams are formed when a gas is released in the system during cure. The gas can either be formed by the curing reaction itself, or from a compound present in the formulation. The technology of gas blown epoxy foam is very similar to that of polyurethane foams. The main difference between the two is in the chemistry of the cure epoxides normally react with curing agent without the evolution of volatiles, and thus required addition of a blowing agent. The isocyanates can, by the addition of water to the system, react to evolve carbon dioxide, which as blowing agents for the foams ${ }^{11}$.

This synergism is explained by an increase in bond formation due to permanent entanglement of chains. In this paper we report the improvement of mechanical properties of aliphatic epoxy resin and vinyl ester resin.

\section{Experimental}

Glycidyl ether of polyol aliphatic epoxy resin has been prepared by reported method ${ }^{12}$ and diaminodiphenylmethane used as a curing agent.

The vinyl ester used in this study was prepared by reacting the commercial epoxy resin says diglycidyl ether of bisphenol-A with methylmethacrylate using imidazole catalyst as reported ${ }^{13}$. The free radical initiator used was benzoyl peroxide (recrystallised from chloroform) activated by $N, N$-dimethyl $p$-toluidine.

\section{Preparation of the IPN foams}

First of all (A) appropriate amount of epoxy resin and hardner were mixed. (B) On other hand vinyl ester and benzoil peroxide, $10 \%$ surfactants were mixed. Surfactant lowers the surface tension of the reactive mixture and thus reducing the free energy associated with dispersion of blowing agent vapor. Finally, the blowing agent was added in the proportion of $20 \%$ by total weight of the resin hardner mixture. The IPN foam formulation for the present work is shown in Table 1 .

Table 1. IPN formulation.

\begin{tabular}{cccccc}
\hline No. & $\begin{array}{c}\text { Epoxy } \\
\text { resin, } \mathrm{g}\end{array}$ & $\begin{array}{c}\text { Epoxy ester, } \\
\mathrm{g}\end{array}$ & $\begin{array}{c}\text { Hardner, } \\
\mathrm{g}\end{array}$ & $\begin{array}{c}\text { Surfactant, } \\
10 \% \mathrm{w} / \mathrm{w}\end{array}$ & $\begin{array}{c}\text { Blowing agent, } \\
20 \% \mathrm{w} / \mathrm{w}\end{array}$ \\
\hline 1 & 100 & 0 & 50 & 10 & 20 \\
2 & 75 & 25 & 50 & 10 & 20 \\
3 & 50 & 50 & 50 & 10 & 20 \\
4 & 25 & 75 & 50 & 10 & 20 \\
\hline
\end{tabular}

Both the resin systems A and B (Scheme 1) weighed and mixed together by a high shear mixture for 4-5 min, operating at approximately $5000 \mathrm{rpm}$. Then the surfactant was added and mixture was again stirred for 5 min. Finally, the blowing agent was added, half in the mixture and other half was poured into the mold for effective blowing. Then mixture was 
poured in the mold. The mold is sealed and placed into a closed air-tight container and it is placed into the oven. Finally, it was cured at $150{ }^{\circ} \mathrm{C}$ for one and half hour.

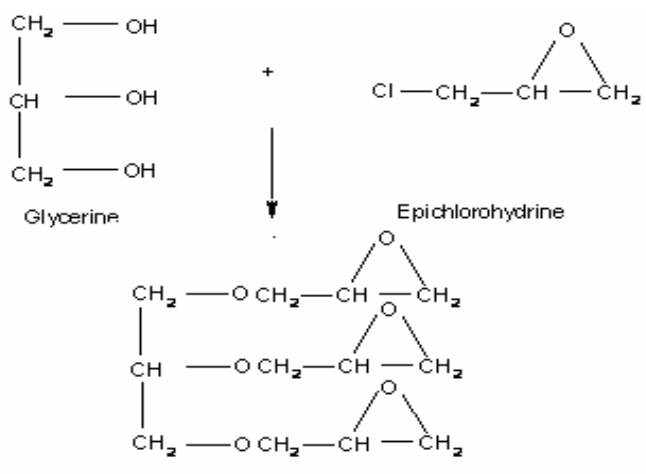

Glycidy ether of polyol aliphatic epoxy

(A)

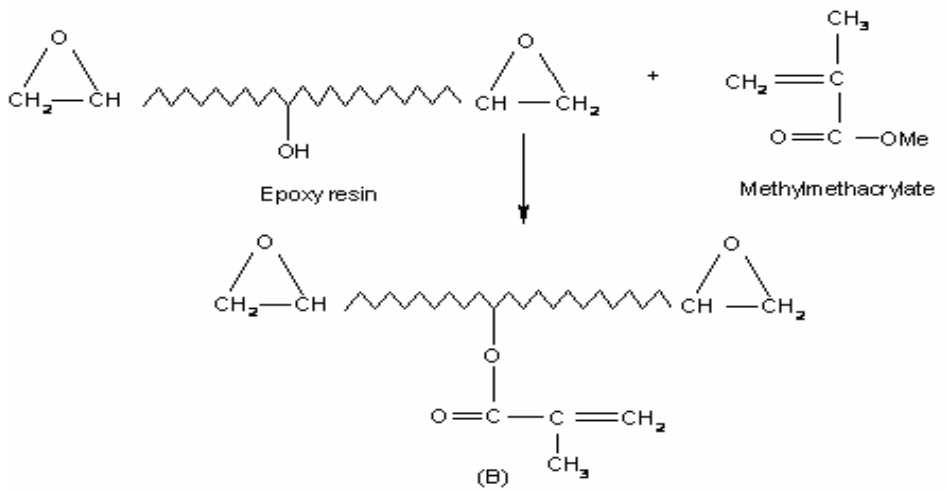

Scheme 1

Density

The density of the foams was determined according to the ASTM method D1622. Density measurements were done for five rectangular samples for each formulation. The test specimens were weighed on a balance. The dimensions of the specimens were determined by using a vernier caliper. Finally, the density was calculated by dividing the weight of the sample by volume of the sample.

\section{Compression test}

Compression test was performed in according to ASTM D1621. Specimens, $40 \mathrm{~mm}$ square by $25 \mathrm{~mm}$ thick were used for this test. In this test specimens were compressed between two stainless steel plates, and load was applied with a crosshead speed of $1.5 \mathrm{~mm} / \mathrm{min}$. Compressive modulus was calculated as the slope of the linear portion of the compression stress-strain curve. The results reported here is the average of five specimens. Compression tests were carried out in both parallel and perpendicular to raise directions.

\section{Thermal property}

Thermal conductivity studies were carried out according to ASTM D5930. A needle probe was used to measure the thermal conductivity, thermal diffusivity and volume heat capacity of the specimens. 


\section{Results and Discussion}

The mechanical, thermal, electrical and chemical properties of the foams are dictated by both its chemical composition and its physical structure. The functionality and chain length of the epoxy resin and curing agents used to determine the crosslink density of the foam, and hence influence its rigidity, strength and temperature resistance. The aromaticity of the resins also affects the mechanical properties of the foams. However, the most important factors influencing foam compressive strength and temperature resistance are the density and cell structure.

All the mechanical properties depend on density. The density of the foam can be adjusted within broad limits. It is determined by the amount of blowing agent and the volume fraction of the unexpanded resin. In this case, some part of the resin remains unexpanded, thus leading to the heavier foam, hence, higher density with increasing resin mixture content.

The compressive strength and modulus for the IPN foams, measured in a direction parallel to the foam rise, are summarized in Table 2 . The strength and modulus decreased with the diglycidyl ether of polyol aliphatic epoxy resin concentration at room temperature and at elevated temperature. The compression modulus and strength are higher than pure epoxy foams. This is attributed to increased crosslink density. The pure epoxy foam has highest crosslink density, which produces higher strength and improves modulus. Crosslink density is frequently represented in terms of molecular weight between crosslink $\left(\mathrm{M}_{\mathrm{c}}\right)$, where higher crosslink densities correspond to lower $\mathrm{M}_{\mathrm{c}}$ values. The pure epoxy foam has the lowest $\mathrm{M}_{\mathrm{c}}$ and thus the highest crosslink density. This explains why the compressive strength and modulus of pure epoxy foam are higher than composite foams. The compressive strength and modulus for the IPN foams, measured in a direction perpendicular to the foam rise, are summarized in Table 3.

Table 2. Compressive modulus and strength parallel to rise.

\begin{tabular}{ccccc}
\hline \multirow{2}{*}{ Sample } & \multicolumn{4}{c}{ Parallel to rise } \\
\cline { 2 - 5 } & \multicolumn{2}{c}{ Modulus (kPa) } & \multicolumn{2}{c}{ Strength (kPa) } \\
\cline { 2 - 5 } Room temp & Elevated temp & Room temp & Elevated temp \\
\hline 0\% Epoxy Ester & 680 & 130 & 584 & 74 \\
25\% Epoxy Ester & 525 & 100 & 503 & 66 \\
$50 \%$ Epoxy Ester & 480 & 83 & 491 & 55 \\
75\% Epoxy Ester & 320 & 62 & 400 & 42 \\
\hline
\end{tabular}

Table 3. Compressive modulus and strength perpendicular to rise.

\begin{tabular}{ccccc}
\hline \multirow{2}{*}{ Sample } & \multicolumn{4}{c}{ Perpendicular to rise } \\
\cline { 2 - 5 } & \multicolumn{2}{c}{ Modulus $(\mathrm{kPa})$} & \multicolumn{2}{c}{ Strength $(\mathrm{kPa})$} \\
\cline { 2 - 5 } & At room temp & At elevated temp & At room temp & At elevated temp \\
\hline 0\% Epoxy Ester & 1.059 & 0.480 & 1.101 & 0.215 \\
25\% Epoxy Ester & 0.901 & 0.280 & 0.980 & 0.102 \\
50\% Epoxy Ester & 0.714 & 0.105 & 0.777 & 0.086 \\
75\% Epoxy Ester & 0.321 & 0.090 & 0.700 & 0.074 \\
\hline
\end{tabular}

Figure 1 shows the variations of thermal diffusivity for the vinyl ester based foam. Figure 2 shows the variations of density for the IPN foam. Figure 3 shows the variations of thermal conductivity for the IPN foams. The thermal conductivity is directly related to the exotherm of the reaction taking place. 


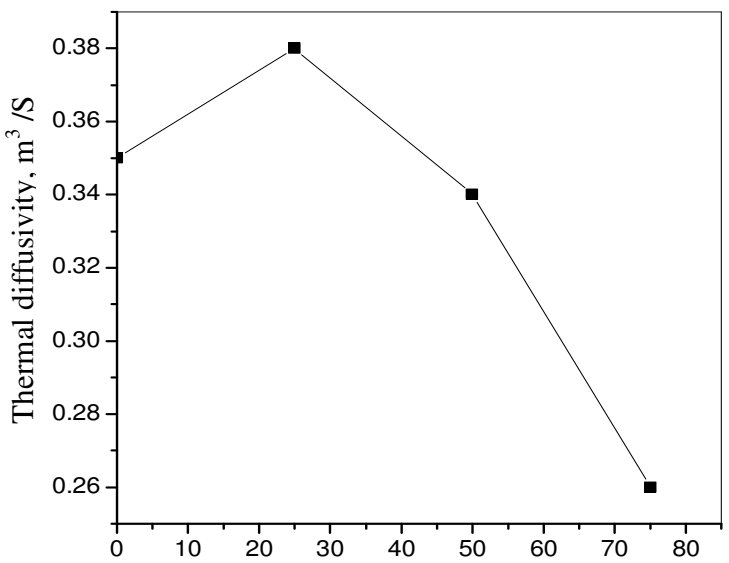

Figure 1. Epoxy ester content \% wt.

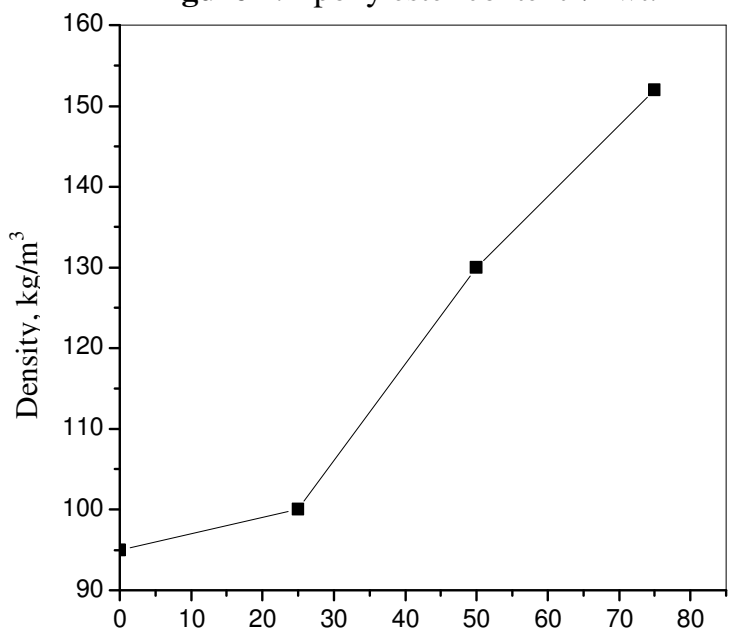

Figure 2. Epoxy ester content \% wt.

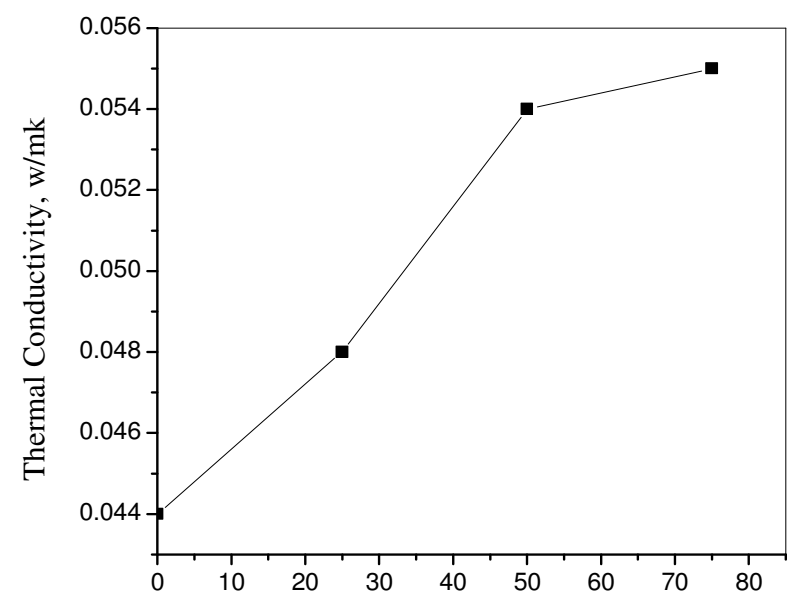

Figure 3. Epoxy ester content \% wt. 
The curing reactions are exothermic, and the rate of reaction increases with temperature. The heat formed by the exothermic reaction can lead to a considerable rise in temperature of system. The heat evolved in the center of the foam cannot readily escape, owing to the low thermal conductivity of the resin and the gaseous interior of the cell structure. Figure 4 shows the increasing trend of specific heat at increasing epoxy ester content.

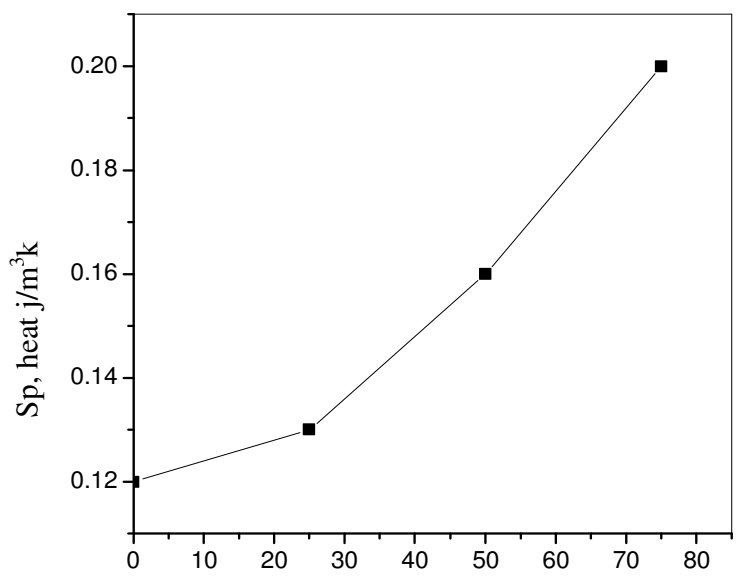

Figure 4. Epoxy ester content $\%$ wt.

Fig 5(a) and 5(b) shows the SEM micrographs of modified epoxy foams and it clearly shows the open cell void of foam having some particle of chemical blowing agents and Fig $5(\mathrm{c})$ is the photograph of Interpenetrating foam.
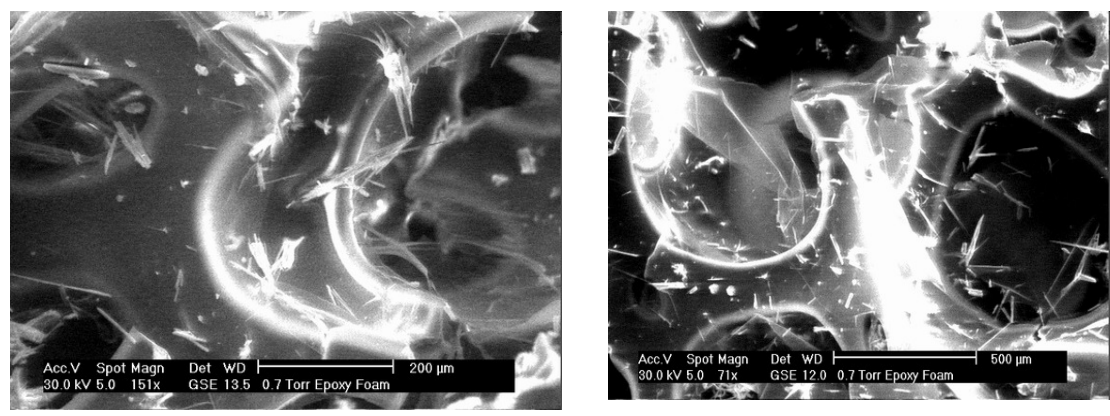

Figure 5a. SEM micrograph of modified Figure 5b. SEM micrographs of epoxy foam. modified epoxy foams.

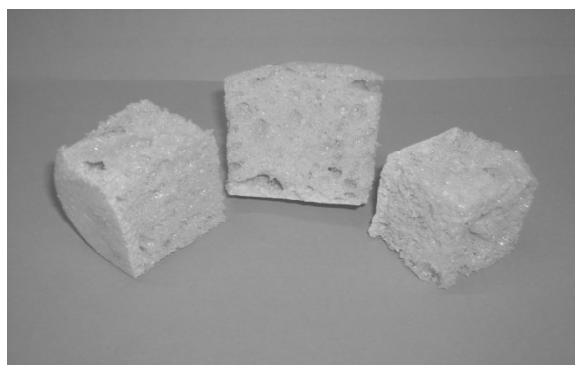

Figure 5c. Photographs of interpenetrating foam. 


\section{Conclusion}

Novel epoxy resin based IPN foams have been prepared. The foams can be prepared easily. The foams have serviceable elasticity with good chemical, physical and mechanical properties. The higher the cross linking higher the density and low mechanical properties.

\section{Acknowledgements}

Authors are thankful to UGC, New Delhi for providing financial assistance. Authors are also very much grateful to Charutar Vidya Mandal, Vallabh Vidyanagar for providing laboratory facilities and encouragement.

\section{Reference}

1. Klempner D and Frisch K, Handbook of Polymeric Foams and Foam Technology, Hanser Verlag, Munchen, 1991.

2. Hajimichael M, Lewis A, Scholey D and Simmonds C, Br Polymer J, 1986, 18, 307-311.

3. Stefani P, Barchi A, Sabugal J and Vazquez A, J Appl Polymer Sci., 2003, 90, 2992-2996.

4. Bledzki A, Kurek K and Gassan J, J Mater Sci., 1998, 33, 3207-3211.

5. Sperling L H, Interpenetrating polymer networks and related materials, Plenum press, New york., 1981.

6. Sperling L H, Thomas D A. and Huelck V, Macromolecules, 1972, 5, 340.

7. Frisch K C, Klempner D, Midgal S, Frisch H L and Ghiradella H, Polym Eng Sci., 1975, 15, 339.

8. Xiao H X, Frisch K C and Frisch H L, J Polym Sci., 1984, 22, 1035.

9. Klempner D and Frisch H L, J Poly Sci., B, 1970, 8, 525.

10. Sperling L H. and Friedmen D W, J Poly Sci., A-2, 1970, 7, 425.

11. Yadav R, Shabeer A, Sundararaman S, Chandrashekhara K, Flanigan V and Kapila, S, Development and Characterization of soy-based epoxy foams; Proceeding of the SAMPE Conference, Long Beach, CA, 2006, May 1-4, pp.1-10.

12. Heath R J, Di Y, Clara S, Hudson A and Manock H, Epoxide Tannage, Loughborough University.

13. Sasidharan Achary P, Joseph D and Ramaswamy R, J Adhesion, 1991, 34,121. 


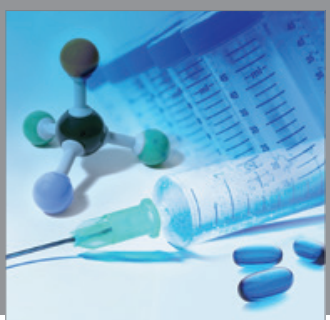

International Journal of

Medicinal Chemistry

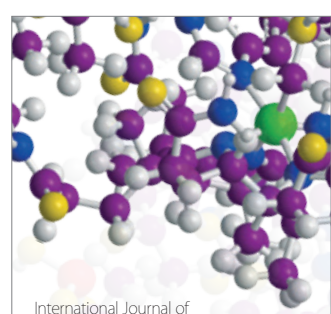

Carbohydrate Chemistry

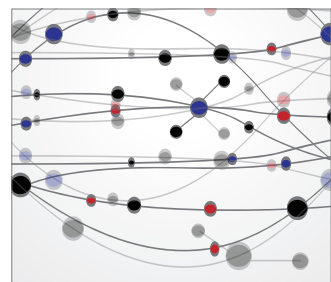

The Scientific World Journal
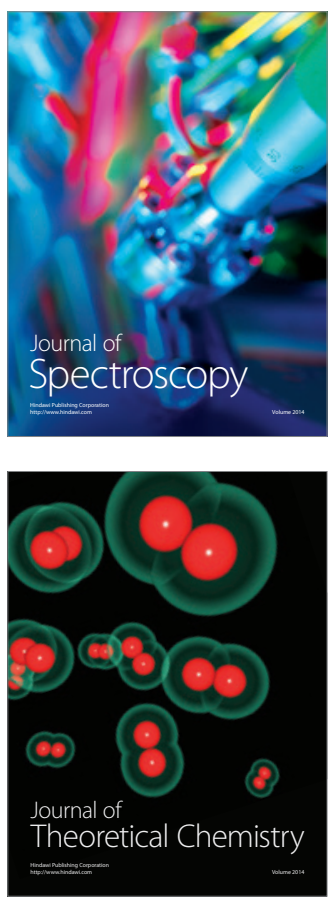
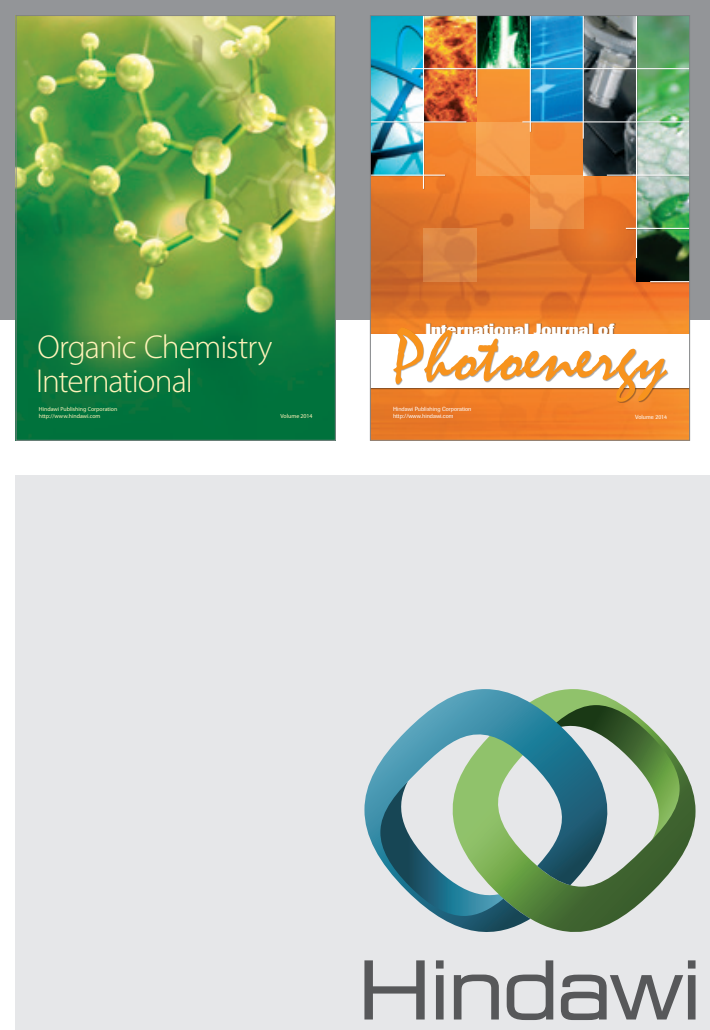

Submit your manuscripts at

http://www.hindawi.com
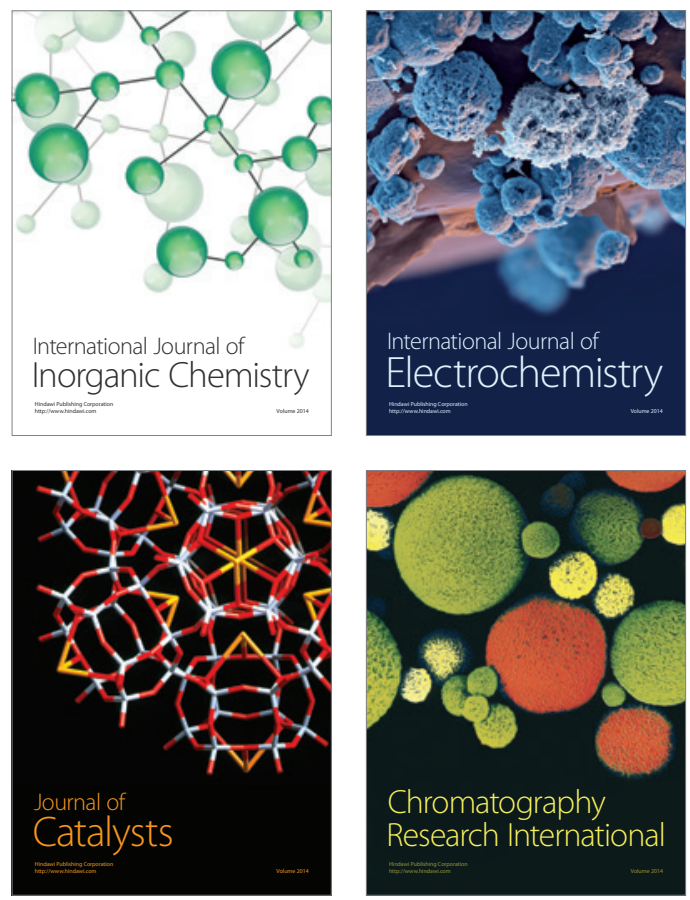
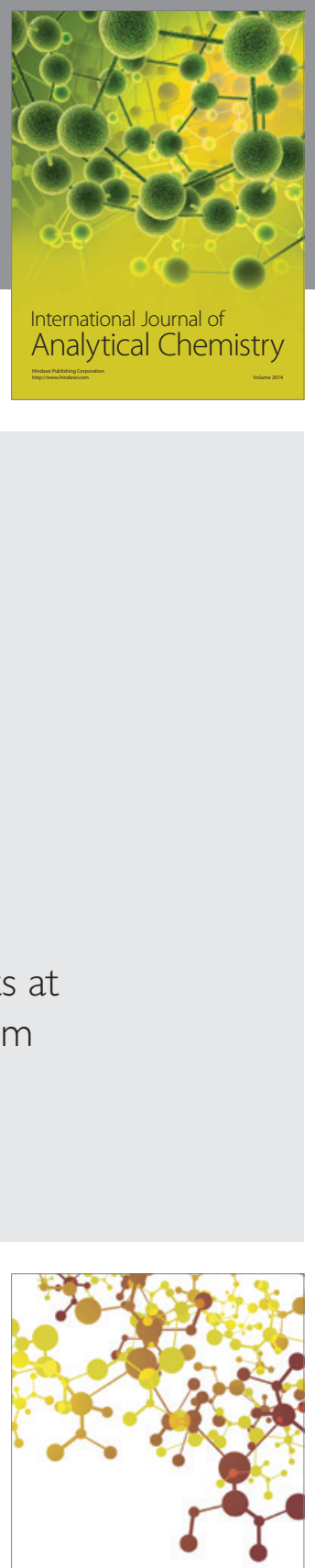

Journal of

Applied Chemistry
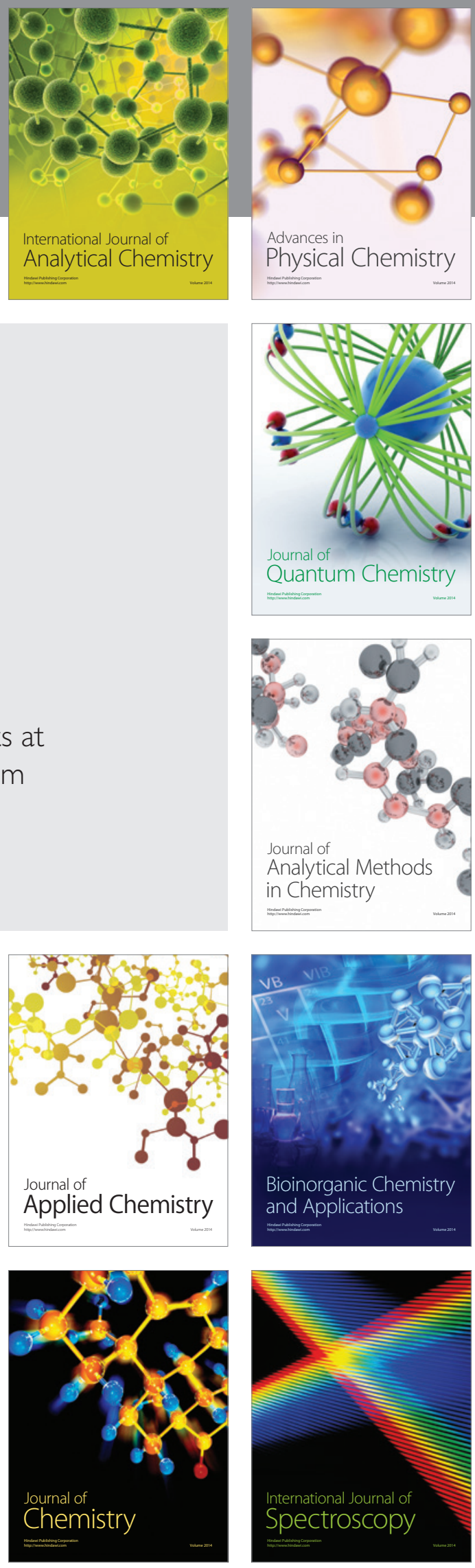